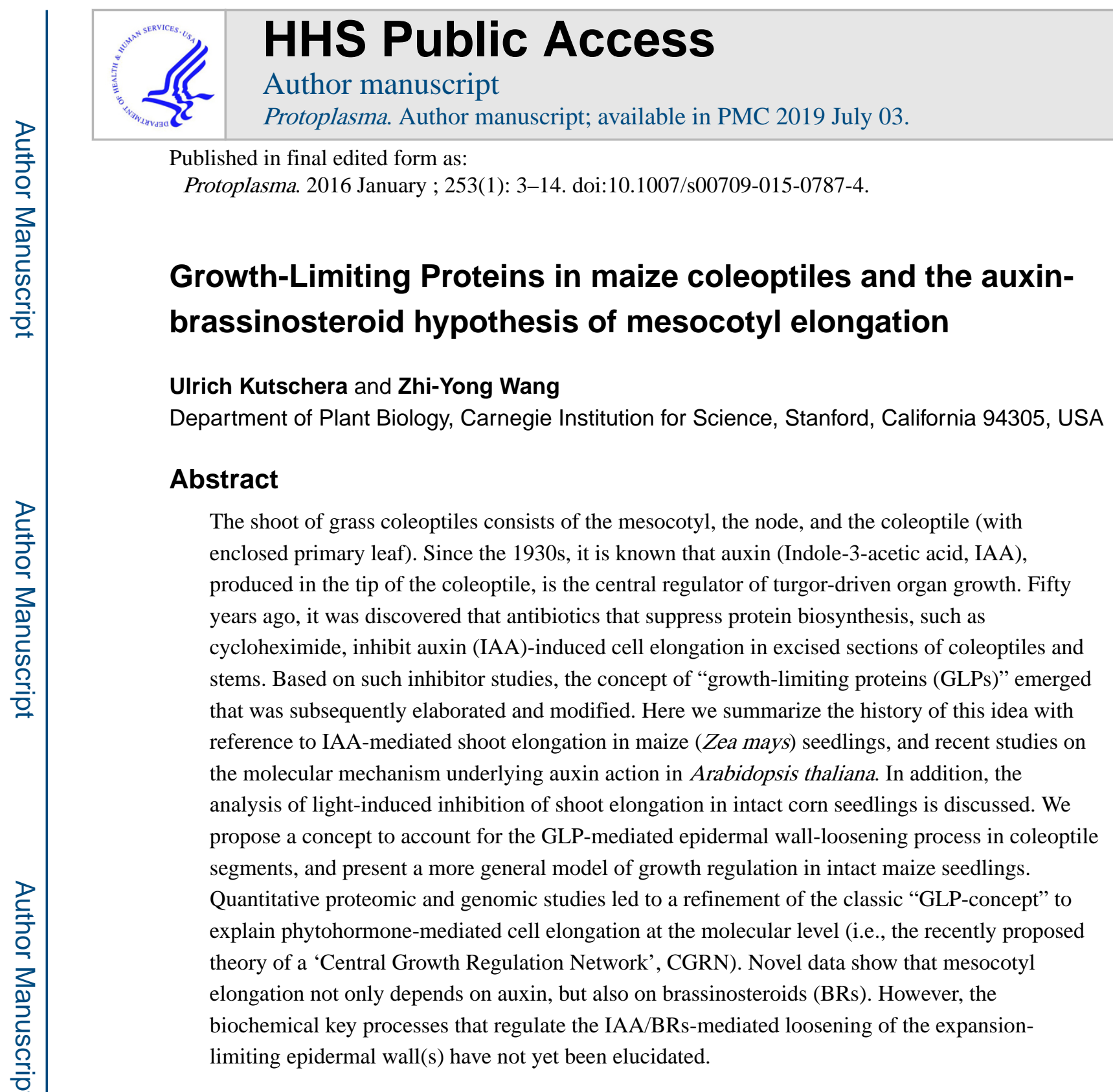

Keywords

Auxin action; brassinosteroids; cell elongation; growth-limiting proteins

\title{
Introduction
}

Land plants (embryophytes), a monophyletic clade of sessile photoautotrophic organisms, are composed of cells that are immobilized due to the presence of cellulosic cell walls (Niklas and Kutschera 2009, 2010). Numerous studies have shown that plant organ growth, which is attributable to cell division and turgor-driven wall expansion, is to a large extend regulated by internal signalling molecules (phytohormones) and environmental cues (light, gravity etc.) which must be integrated at intracellular and organismic levels (Teale et al. 2006; Wang et al. 2012, 2014; Oh et al. 2014). As one attempt, plant biologists have adopted

kut@uni-kassel.de. 
two major experimental approaches to elucidate the mechanism(s) that regulate growth and development: The section test and intact-seedling-assays.

Since the discovery of the phytohormone auxin (indole-3-acetic acid, IAA), researchers have used excised sections cut from the shoots of grass seedlings (coleoptiles or mesocotyl), incubated these organ fragments in aerated aqueous solutions (+/- IAA), and analysed the resulting growth response of these organ fragments (Went and Thimann 1937). During the 1940s, IAA was isolated from kernels of maize, and this crop plant was primarily employed to elucidate the biosynthesis of this phytohormone (Srivastava 2002; Woodward and Bartel 2005; Kriechbaumer et al. 2006; Abel and Theologis 2010; Zažimalovià et al. 2014).

The seedlings of cereals, such as oats, rice or maize (Zea mays) (Fig. 1 a) are the favoured model systems for the study of coleoptile (or mesocotyl) growth in vitro in response to exogenously applied IAA. Alternatively, intact seedlings can be raised under different environmental conditions (for instance, $+/$ - light) to modulate the rate of organ growth in the intact system (in situ). In recent decades, the hypocotyl of Arabidopsis thaliana has been a favoured model system for studying the regulation of cell elongation by hormones and environmental signals (Deng et al. 2014). Combined with genetics and proteomics technologies, these approaches have yielded deep insights into the molecular basis of the regulation of cell growth and, in addition to IAA, brassinosteroids (BRs) were found to be of central importance (Bai et al. 2012 a, b; Hartwig et al. 2011, 2012; Wang et al. 2012; Makarevitch et al. 2012; Kutschera and Wang 2012; Zhu et al. 2013; Oh et al. 2014).

Using both experimental systems, it became clear that cell elongation, the central process governing organ growth, consists of turgor-driven expansion of the cell walls. In addition, the plastic deformation (rather than elastic stretching) of these intramural polymeric networks, which includes cell wall and protein biosynthesis, was found to be the ratelimiting process. This classic "plasticity theory" has been corroborated and refined by generations of plant physiologists, and accumulating data document that the thick, expansion-limiting outer epidermal wall(s) are the sites where growth is regulated at the biophysical level (Baskin 2005; Kutschera 2008 a, b; Kutschera and Niklas 2007, 2009, 2013; Lipchinsky et al. 2013).

Despite these insights, the biochemical basis of cell elongation remained a mystery. The situation changed during the early 1960s, when certain inhibitors of protein- and RNAbiosynthesis became available. Based on numerous inhibitor studies, the concept of 'growthlimiting proteins' (GLPs) emerged.

In this article, we first describe the history of this idea and its current status. Then, we summarize recent studies that document an as yet unexplored auxin (IAA)-brassinosteroid (BR)-interaction in grass seedlings, notably in maize. Finally, we propose a novel IAA-BRhypothesis of mesocotyl elongation with reference to the recently discovered intracellular 'Central Growth Regulation Network' (CGRN) (Fan et al. 2014; Oh et al. 2014; Wang et al. 2012, 2014). 


\section{Auxin and shoot development}

The classic "auxin-hypothesis" of coleoptile elongation originated with the work of Fritz Went (1903-1990), who introduced the "excised coleoptile tip/Agar block"-bioassay as a tool for the study of phytohormone action in etiolated grass seedlings (Went 1928). In a subsequent book, Went and Thimann (1937) coined the famous phrase "without auxin no growth", which originally applied to the coleoptile of cereal seedlings (oats, wheat, maize). In these organs, the tip was found to be the sole site of IAA production, and a basipetal flow of auxin from this "source" to the base of the coleoptile induces cell elongation in this sheath-like organ (Woodward and Bartel 2005; Nishimura et al. 2011; Mori et al. 2005; Briggs 2014). However, the question as to the importance of IAA with respect to the elongation of the mesocotyl (i.e., the axial organ below the node) (Fig. 1 b) remained unclear.

With reference to the work of van Overbeek (1936), who had studied light-induced inhibition of mesocotyl elongation in maize seedlings, it was concluded that "The growth of the mesocotyl is ... entirely dependent on the auxin which reaches it from the base of the coleoptile" (Went and Thimann 1937, p. 84). Hence, the "auxin hypothesis of shoot elongation" states that both the growth of the coleoptile and that of the mesocotyl are regulated by a flow of IAA, from the tip of the coleoptile to the base of the shoot. Accordingly, light-induced inhibition of growth (notably that of the mesocotyl) should be regulated via a reduced supply of auxin (Mer 1951).

Vanderhoef and Briggs (1978) summarized the pertinent evidence for this concept and concluded that, based on their data on red light-inhibited mesocotyl elongation in maize seedlings, light regulates organ growth by controlling the supply of IAA from the coleoptile. Using the same plant material, Iino (1982) concluded that red light inhibits mesocotyl elongation mainly by reducing the auxin supply from the coleoptile, and Jones et al. (1991) documented that this light effect on the decrease in the level of IAA occurs in the growthcontrolling epidermal cells of the mesocotyl (see also Iino and Carr 1982; Barker-Bridges et al. 1998).

More recently, Borucka and Fellner (2012) corroborated and extended the "auxin hypothesis of shoot elongation" in maize seedlings. The authors documented that Auxin Binding Protein 1 (ABP1), a putative ER-/plasma membrane-associated IAA-receptor involved in the regulation of cell expansion of the maize coleoptile (Shishova and Lindberg 2010; Ljung 2013), is a component of the auxin-light-signalling network in this crop species (Borucka and Fellner 2012). In summary, these data support the classic concept that IAA is the key growth regulator in developing shoots of maize seedlings (Barker-Bridgers et al. 1998).

\section{Protein synthesis as a growth-limiting process}

Despite the fact that auxin was identified as the most important regulator of shoot development in etiolated grass seedlings several decades ago, the biochemical basis of phytohormone action remained elusive. 
In 1964, plant physiologists discovered that IAA-induced elongation of excised segments cut from the sub-apical (growing) region of stems or coleoptiles/mesocotyls is inhibited by antibiotics known to suppress protein biosynthesis. In a seminal study, Noodén and Thimann (1963) used chloramphenicol, puromycin, and p-fluorophenylalanine as experimental tools and discovered that all three substances inhibit IAA-mediated segment elongation to a similar extend. Moreover, in the presence of chloramphenicol, both the hormone-induced growth process and the incorporation of radioactively labelled ${ }^{14} \mathrm{C}$-leucine into the fraction of soluble proteins were inhibited in parallel. However, in pea stem- and oat coleoptilesections, IAA did not promote the incorporation of ${ }^{14} \mathrm{C}$-leucine, i.e., biosynthesis of total cytoplasmic protein was not enhanced by the plant hormone. Despite this lack of a positive IAA-effect the authors concluded that "synthesis of some one protein present in differing amounts in different tissues, is a factor limiting growth" (Noodén and Thimann 1963).

In a subsequent study carried out with sections cut from the hypocotyl of soybean (Glycine max) and the mesocotyl of maize seedlings (Fig. 1b), Key and Ingle (1964) confirmed and extended Noodén and Thimann's (1963) findings. The authors used specific inhibitors of RNA synthesis, which suppress IAA-induced growth, and concluded that "cell enlargement ... appears to be under the control of the genome through the synthesis of intermediate, messenger-RNA molecules" (Key and Ingle 1964). In a subsequent report, Key (1964) summarized the GLP-concept as follows: "Presumably the rate of formation of some specific RNA is enhanced by auxin ... leading to an increased supply of some limiting enzyme or enzyme system" (see also the accompanying report of Key and Shannon 1964). Numerous subsequent studies corroborated these early findings (Key 1969).

Using the protein synthesis inhibitor cycloheximide (CHX) as a tool, Cleland (1971) documented that IAA-induced cell-wall loosening, which causes turgor-driven organ growth, is inhibited by CHX in parallel to the suppression of elongation and protein biosynthesis. Detailed time-course studies led to the conclusion that auxin-mediated elongation is dependent on the biosynthesis (or presence) of a "growth-limiting protein" (GLP), which may be an enzyme that cleaves wall crosslinks, a wall polysaccharide hydrolase, or a transport protein responsible of the movement of a "wall-loosening factor" across the plasma membrane (Cleland 1971). Based on experiments with lupin hypocotyl sections, similar conclusions were reached by Penny (1971) (see Bates and Cleland 1979 for a summary of these and related studies).

After the discoveries that IAA-mediated growth can be induced within 15 min of hormone application (Figs. 2a, b), and the characterization of the "acid-growth effect" in coleoptile segments (see below), the classic theory that cell elongation may be limited by the continued biosynthesis of specific proteins (and the associated "gene activation hypothesis") was largely abandoned (Dietz et al. 1990; Abel and Theologis 2010). However, after the discovery of IAA-induced fine-structural changes along the growth-controlling outer epidermal wall (OEW) in maize coleoptiles, the GLP-concept was re-vitalized. This era of auxin research is summarized in the next section. 


\section{Coleoptile elongation: Acid growth and osmiophilic nanoparticles}

A series of studies led to the hypothesis that IAA may cause the initiation of cell elongation via the rapid activation of a specific protein, the so-called "proton-secreting plasma membrane $\mathrm{H}^{+}$-ATPase". The resulting acidification of the apoplastic space via activation of specific "wall-loosening proteins" (such as expansins) was thought to cause an enhancement in wall plasticity, and hence the initiation of turgor-driven organ elongation (Brummell and Hall 1987; Cosgrove 1997, 2005; Hager 2003; Benjamins and Scheres 2008; Takahashi et al. 2012). However, a comparative quantitative analysis of the effects of IAA and the fungal phytotoxin Fusicoccin (FC) on growth and proton secretion in coleoptiles of maize and oats (Avena sativa) led to the conclusion that FC, but not IAA, causes wall-loosening and cell enlargement via a rapid acidification of the cell walls. This "acid-growth theory of FCaction", which is compatible with the "expansin-concept of wall-loosening", is well supported by numerous independent lines of evidence (Schopfer 1993; Kutschera 1994, 2001, 2003, 2006; Karcz and Burdach 2007; Niklas and Kutschera 2012; Visnovitz et al. 2013; Burdach et al. 2014; Rudnicka et al. 2014).

If IAA-induced proton secretion is insufficient to cause wall loosening in coleoptiles, how can this plant hormone enhance cell expansion in this organ? Based on the premise that the thick, expansion-limiting outer epidermal wall (OEW) of the coleoptile represents the growth-controlling structure of the organ (Brummel and Hall 1987; Lipchinsky et al. 2013), the occurrence of IAA-induced osmiophilic (electron-dense) nano-particles along the OEW was documented (Fig. 3a, b). These granules (diameter ca. $300 \mathrm{~nm}$ ), which fuse with the OEW, were also found in intact (growing) coleoptiles; after cutting of the segments, the granules disappeared and rapidly re-appeared upon incubation in IAA, in correlation with the induction of cell elongation (Kutschera et al. 1987). In the presence of the protein synthesis inhibitor CHX, auxin is unable to cause growth, and no nano-particles were observed along the OEW (Fig. 3c). Since FC and acid (buffers of pH 4) induce growth, but no nano-particles, these granules have been interpreted as IAA-dependent "cell wallloosening complexes" (Vaughn 2002; Edelmann et al. 1995; Edelmann and Kutschera 1993; Niklas and Kutschera 2012).

A series of studies revealed that IAA rapidly promotes the incorporation of ${ }^{3} \mathrm{H}$-leucine into the OEW, whereas the biosynthesis of cellulose, hemicelluloses and pectins were unaffected by the hormone. CHX prevented this rapid IAA-effect on the biosynthesis of wall protein, and monensin, an inhibitor that causes dysfunction of the Golgi apparatus, had a similar effect (Schindler et al. 1994). Taken together, these studies led to the conclusion that the epidermal GLPs are causally involved in the initiation of growth: the "wall-loosening factor" may be a Golgi-derived proteinaceous component of the OEW, which represents glycoproteins visible as nano-particles along the extension-limiting peripheral organ wall (Fig. 3a, b). However, the exact composition of these growth-related granules has not yet been elucidated, although there is strong evidence indicating that they contain Oglycosylated proteins that are incorporated into the OEW (Edelmann and Schopfer 1989; Hoffmann-Benning et al., 1994; Schindler et al. 1994; Edelmann et al. 1997; Kutschera and Edelmann 2005; Niklas and Kutschera 2012). 
The validity of the inhibitor studies summarized above (Fig. 3c) rests on the assumption that cycloheximide (CHX) acts as a specific agent to block protein synthesis inhibitor (see Kutschera and Schopfer 1986 for a discussion of this topic). Over the past decades, CHX, which was originally isolated from the bacterium Strepromyces griseus, has been employed to inhibit eukaryotic translation (Bates and Cleland 1979), but the exact mode of action remained elusive. More recently, a detailed study revealed that, in eukaryotic cells, CHX is in fact a molecule that interferes specifically with translation elongation in eukaryotic cells. Within the cytoplasm, CHX binds to the E-site of the 60S ribosome, and hence blocks eEF2mediated mRNA-tRNA translocation (Schneider-Poetsch et al. 2010; Olivier 2014).

This new insight is of importance with respect to the GLP-concept proposed fifty years ago (Key 1964; Key and Ingle 1964; Key and Shannon 1964), which is supported by physiological, biochemical and cytological data. When the translation of RNA and the resulting biosynthesis of protein(s) is blocked, three processes, glycoprotein-secretion, biomechanical wall-loosening, and turgor-driven cell expansion are inhibited. These data support the GLP-concept of coleoptile elongation, although the correlations described here do not strictly prove a cause- and effect-relationship.

\section{Solute uptake and turgor maintenance}

Figure $2 \mathrm{~b}$ shows that, during the first $4 \mathrm{~h}$ of IAA-treatment, coleoptile elongation in water proceeds at a constant rate. However, $2 \mathrm{~h}$ later, the growth slows down and ceases after one day in the presence of auxin (Kutschera and Schopfer 1986). This decline in organ elongation is, in part, due to a loss of turgor pressure caused by the dilution of vacuolar contents as a result of continued water absorption.

In a seminal study, Stevenson and Cleland (1981) have shown that cessation of coleoptile elongation in water can be prevented by the addition of absorbable solutes, such as sucrose or potassium chloride $(\mathrm{KCl})$. However, $24 \mathrm{~h}$ after start of IAA-incubation, organ elongation slows down and ceases, due to the fact that the cells have reached their final length. Sucrose, at a concentration of $50 \mathrm{mM}$, has been used as a "natural" solute to maintain IAA-induced coleoptile growth over several $\mathrm{h}$, and it is likely that Suc, which elicits a strong medium acidification response, is actively taken up by the phloem cells via ATP-dependent processes (Kutschera 1994; Kutschera et al. 2010).

However, turgor- and osmoregulation (i.e., the maintenance of cell osmotic pressure during long-term growth) can also be achieved by the addition of $\mathrm{KCl}(10 \mathrm{mM})$ to the incubation medium (Stevenson and Cleland 1981). There is evidence indicating that $\mathrm{K}^{+}$-ions are required for the initiation of IAA-mediated coleoptile elongation, and potassium channels plus the $\mathrm{H}^{+}$-ATPase-system (i.e., specific plasma membrane-integrated protein complexes) may be involved in this process (Claussen et al. 1997; Becker and Hedrich 2002). Moreover, Burdach et al. (2014) have shown that, after the addition of IAA, the uptake of $\mathrm{K}^{+}$(and $\mathrm{Cl}^{-}$)ions is associated with the promotion of coleoptile elongation. Hence, $\mathrm{K}^{+}$-specific, activated ion channels, which act in combination with the ATP-dependent $\mathrm{H}^{+}$-secretion-process, may qualify as GLPs in the grass coleoptile. 
However, this hypothesis is incompatible with the finding that, in the presence of sodium chloride $(\mathrm{NaCl})$ (instead of $\mathrm{KCl}$ ), normal IAA-induced growth occurs, but proton secretion is largely inhibited by $\mathrm{Na}^{+}$-ions. In contrast, fusicoccin-mediated $\mathrm{H}^{+}$-secretion and cell elongation occurs in KCl- and NaCl-solutions at the same rates (Kutschera 1994, 2006). These data are consistent with the tenets of the acid-growth theory of FC action in the grass coleoptile, but not with the $\mathrm{H}^{+}$-secretion $/ \mathrm{K}^{+}$-uptake model of IAA action in the same plant organ.

\section{Proteomics and the search for GLPs in grass coleoptiles}

Three recent proteomic studies attempted to resolve the question as to the nature and role of GLPs in developing grass seedlings (Kutschera et al. 2010; Deng et al. 2012; Li et al. 2013). In two comprehensive analyses, coleoptiles of rye (Secale cereale) were used as experimental system, and membrane-associated protein extracts were studied using twodimensional difference gel electrophoresis (Kutschera 2010; Deng et al. 2012). Within $2 \mathrm{~h}$ of auxin treatment, 16 protein spots were up- or down-regulated. Protein identification by use of reverse-phase liquid chromatography/electrospray tandem mass spectrometry revealed 4 epidermal proteins of special interest. Two of these, a small Ras-related GTP-binding protein and a subunit of the $26 \mathrm{~S}$ proteasome, were rapidly (within $30 \mathrm{~min}$ ) down- or up-regulated by IAA, respectively, and may therefore qualify as GLPs. However, the role of these rapid IAA-modulated epidermal proteins with respect to the "cell wall loosening-complexes" (Hoffmann-Benning et al. 1994; Vaughn 2002; Niklas and Kutschera 2012) remains unclear (Deng et al. 2012).

Using coleoptile segments cut from 4-day-old etiolated maize seedlings (Fig. 1b), Li et al. (2013) analyzed the long-term effect of IAA (treatment for $4 \mathrm{~h}$, see Fig. 2b). The authors restricted their search for GLPs to the outer epidermis of this sheath-like organ. They discovered, by use of a combination of proteomics- and PCR-analyses, 15 proteins that are (or may be) involved in cell wall (or cutin) biosynthesis. Two newly discovered epidermal proteins with unknown functions (denoted by the authors as Hyp 3 and Hyp 4) may be associated with the wall-loosening process and hence qualify as GLPs. However, as in the complementary studies on rye coleoptiles (Kutschera et al. 2010; Deng et al. 2012), the authors failed to identify wall-associated proteins that are unequivocally associated with the osmiophilic (growth-related) nano-particles depicted in their paper (see Fig. 1 in Li et al. 2013). Therefore, the exact composition and physiological significance of the "epidermal wall-loosening complexes" (Vaughn 2002) remains unresolved.

It has been suggested that these granules are related to the biosynthesis of the cuticle, a structure that modifies the mechanical properties of the outer epidermal wall and hence may influence the rate of cell elongation (Hoffmann-Benning et al. 1994; Edelmann et al. 2005). However, evidence of support of this hypothesis is currently lacking.

\section{Expansins and extensins}

In none of these recent quantitative proteomic studies on growing vs. non-elongating organ segments (Kutschera et al. 2010; Deng et al. 2012; Li et al. 2013), the suggested roles of two 
non-enzymatic cell wall proteins, expansins and extensins, respectively, has been elucidated. Expansins are endogenous wall-associated proteins that mediate acid-induced growth in axial plant organs, such as hypocotyls of etiolated seedlings (McQueen-Mason et al. 1992; Cosgrove 2005). Experiments with wheat (Triticum aestivum) coleoptiles have contributed greatly to our knowledge on the possible role of these cell wall proteins in the regulation of organ growth. In a seminal study, Gao et al. (2008) documented that expansin activity, measured in heat-inactivated cell walls, displays a pH-optimum of ca. 4.0 to 4.5 . This value is in accordance with the $\mathrm{pH}$ established in the cell walls of grass coleoptiles sections treated with the fungal phytotoxin FC (Schopfer 1993; Kutschera 1994, 2006; Burdach et al. 2014; Rudnicka et al. 2014). Hence, FC-induced cell wall expansion appears to be mediated by expansins, which acts by disrupting H-bonds between cellulose microfibrils and matrix polymers (Gao et al. 2008; Zhao et al. 2011). However, despite these insights, the molecular basis of expansin action in muro, i.e., the loosening of the wall by weakening the noncovalent bonding of polysaccharides to one another, is still unclear (Georgelis et al. 2012; Lipchinsky 2013). With respect to the mature, flowering maize plant (Fig. 1 a), (B)expansins were found to be important components of pollen grain (male gametophyte)specific wall proteins. The so-called group-1 pollen allergens ( $\beta$-expansins, Zea $\mathrm{m} 1$ ) have been found to be involved in the growth and competitive ability of pollen tubes on the stigma/style of the female silk in the sporophyte of sexually reproducing corn (Valdivia et al. 2007).

Extensins, on the other hand, appear to cross-link (stiffen) the walls during cessation of organ growth (Cosgrove 1997; Lamport et al. 2011, 2014). However, the exact mode of these wall-stiffening processes remain unexplained. It should be noted that there is no evidence indicating that the "growth-related nano-particles" discovered and extensively characterized along the OEW of growing coleoptiles (Fig. 3a, b) contain expansins or extensins. However, these structures have also been found in expanding axial organs of many mono- and dicotyledonous plants (Samajova et al. 1998). Microscopical investigations indicate that these granules also occur at the OEW of the mesocotyl (Cona et al. 2003). The structure, function and development of this axial plant organ is discussed in the next section.

\section{Mesocotyl elongation: enzyme-mediated wall stiffening}

As mentioned in the Introduction, the concept of GLPs was developed to a large extent based on experimental results obtained with excised sections of the mesocotyl cut from etiolated maize seedlings (Key and Ingle 1964; Shannon et al. 1964). As documented in these pioneering studies, the region of mesocotyl elongation is restricted to about $10 \mathrm{~mm}$ below the node, and IAA (as well as the synthetic auxin 2,4-D; see Song 2014) rapidly promotes cell elongation in this organ, as it does in the coleoptile.

Figure 4a shows that split sections, cut from the coleoptile and mesocotyl of etiolated maize seedlings, display a spontaneous outward bending response upon incubation in water. After application of auxin, an inward curvature of the split halves occurs, documenting that the outer epidermis is the primary IAA-responsive tissue (Went and Thimann 1937; Kutschera et al. 1987). The same phenomenon occurs in excised mesocotyl sections (Fig. 4b). This 
finding indicates that, in this organ, the epidermal cell layer likewise regulates the growth of the entire system.

Although the mesocotyl of maize seedlings has been used, in addition to coleoptiles, as experimental system by generations of plant physiologists (van Overbeek 1936; Borucka and Fellner 2012), it is still unknown whether or not these organs display the same sensitivity towards added IAA (Went and Thimann 1937). In order to fill this void in our knowledge, the experiments described below were carried out.

Figure $2 \mathrm{a}$ shows that, after $24 \mathrm{~h}$ of incubation in auxin, both the coleoptile and the mesocotyl display about the same growth response (length increase: ca. $+2 \mathrm{~mm}$ in the control, and ca. $+7 \mathrm{~mm}$ in the presence of IAA, respectively). Moreover, Fig. $2 \mathrm{~b}$ documents that, over the first $4 \mathrm{~h}$ of treatment, the kinetics of IAA-induced coleoptile- and mesocotyl elongation are very similar. Within $30 \mathrm{~min}$ of auxin application, cell elongation is promoted, and reaches a constant value between hours 1 and 4 after start of the experiment. Hence, in etiolated maize seedlings, both organs of the developing shoot display essentially the same sensitivity towards applied IAA. Since auxin exerts a rapid response in the coleoptile as well as in the mesocotyl, the auxin receptor ABP1-mediated signalling pathway appears, in both organs, to represent the first step in the processes leading to enhancement of growth (Jones et al. 1991; Woodward and Bartel 2005; Teale et al. 2006; Xu et al. 2010; Shishova and Lindberg 2010; Ljung 2013). Moreover, these growth measurements (Fig. 2a, b) further corroborate the "auxin hypothesis of shoot elongation" described above.

Upon exposure of intact, etiolated seedlings to light, mesocotyl elongation is rapidly inhibited via a reduction in IAA supply (van Overbeeck 1936; Mer 1951; Vanderhoef and Briggs 1978; Iino 1981; Jones et al. 1991). The biochemical mechanism of this retardation of shoot elongation, with respect to GLPs, has been analyzed in detail. Yahalom et al. (1987) have shown that the well-known light-mediated inhibitory effect on mesocotyl elongation in maize mesocotyls is reversible: when the irradiated seedlings are placed back into darkness, the rate of growth increased and reached the level before light-treatment. Moreover, retardation in mesocotyl growth in light was found to be due to a decrease in cell wall extensibility (Yahalom et al. 1988).

Using etiolated maize seedlings as experimental system, Schopfer et al. (2001) demonstrated a positive correlation between light-induced inhibition of mesocotyl extension, an increase in wall stiffness, and the incorporation of lignin into the growth-controlling outer walls of this organ. In a subsequent report, Cona et al. (2003) documented that, upon light treatment, the abundance of a hydrogen peroxide $\left(\mathrm{H}_{2} \mathrm{O}_{2}\right)$-producing enzyme, polyamine oxidase (PAO), increases in the growth-controlling epidermal walls of the maize mesocotyl. This biochemical process may be due to a peroxidase-catalyzed cross-linking and lignification in the thickened epidermal walls. Hence, PAO may qualify as a GLP in the mesocotyl of maize seedlings. Moreover, Cona et al. (2003) suggested that light-induced PAO gene expression in the epidermis is mediated by phytochrome-dependent transcriptional activators. However, more work is required to further corroborate this hypothesis, notably with reference to the occurrence of the growth-associated granules described above (Fig. 3a, b). 
In summary, the studies described here show that light-induced inhibition of mesocotyl elongation in intact seedlings, caused by reduced IAA supply, is due to an enzyme (GLP)mediated wall stiffening process. PAO appears to be one wall-associated key enzyme, but other apoplastic GLPs may also be involved (Okamoto-Nakazato 2002; Frankova and Fry 2013; Lamport et al. 2014).

\section{Role of brassinosteroids during shoot development}

In 1979, the discovery of a novel steroidal lactone, isolated from pollen of rape (Brassica napus), was reported. Over the subsequent decade, in addition to this first brassinosteroid (called brassinolide), numerous related poly-hydroxylated steroidal plant hormones were isolated and characterised. Today, more than 60 different brassinosteroids (BRs) are known that are involved in the regulation of plant growth and development (Kim and Wang 2010; Wang et al. 2012; Kutschera and Wang 2012; Hao et al. 2013; Zhu et al. 2013).

Biosynthesis of BRs, their modes of action and signalling pathways have been studied in the model plant Arabidopsis thaliana, as well as in crop species such as tomato, pea and rice. However, comparatively little is known about the role of BRs during seedling development in cereals such as maize, despite the fact that endogenous brassinosteroids are synthesized in the roots of etiolated corn seedlings (Kim et al. 2005). Experiments with seedlings of garden cress (Lipidium sativum), a relative of rape and model organism for the study of root phototropism (Kutschera and Briggs 2012), revealed that the triazole compound propiconazole ( $\mathrm{Pcz}$ ) acts as a specific inhibitor of BR biosynthesis (Sekimata et al. 2002).

Using Pcz as a tool, and by isolation of the first BR-deficient maize mutant, Hartwig et al. (2011) documented that mesocotyl elongation in dark-grown maize seedlings is inhibited by this triazole compound, indicating that BRs are involved in the regulation of organ growth. In a subsequent study, Hartwig et al. (2012) compared the effect of Pcz on developing seedlings of Arabidopsis and Z. mays. In both types of plants, organ development was drastically reduced.

Makarevitch et al. (2012) isolated and characterized a brassinosteroid-deficient mutant in maize, brd1-m1. This mutant of $Z$. mays is defective in brassinosteroid biosynthesis and therefore largely lacks a mesocotyl. Physiological experiments, summarized in Fig. 5, document that the short mesocotyl-phenotype of brd1-m1 plants can be largely rescued by the addition of brassinolide (BL) (Makarevitch et al. 2012). These mesocotyl studies show that organ elongation in etiolated maize seedlings is not only dependent on IAA, but is also a BR-regulated process. Since, in seedlings of Arabidopsis, auxin stimulates BR biosynthesis (Chung and Choe 2013), it is likely that these growth regulators likewise interact in the maize mesocotyl.

There is little evidence that BR influences the elongation growth of the grass coleoptile (Hartwig et al. 2011, 2012). This process appears to be exclusively dependent on the supply of IAA produced in the tip of the organ (Went and Thimann 1937; Iino 1982; Kutschera 2003; Mori et al. 2005; Nishimura et al. 2011; Briggs 2014). 


\section{Auxin-brassinosteroid-interactions and the CGRN}

The "cross-talk" between IAA and BRs in the regulation of mesocotyl elongation in maize seedlings is unknown, and the role of the GLPs in these hormone interactions largely unexplored. However, our "split section" experiment shown in Fig. 4b documents that mesocotyl elongation is restricted to, and hence controlled by, the epidermal cell layer. Therefore, we suggest that BR-action is, like that of IAA, localized in the peripheral cell layer, and genetic evidence from Arabidopsis supports this hypothesis (Savaldi-Goldstein et al. 2007).

Ten years ago, two independent research groups reported that, in the dicot plant Arabidopsis thaliana, auxin and brassinosteroids exert overlapping effects on the patterns of gene expression. Moreover, it was suggested that a shared IAA/BR-pathway is required for the regulation of hypocotyl elongation in this model organism (Goda et al. 2004; Nemhauser et al. 2004). Subsequent investigation identified several molecular connections between the BR- and auxin-signalling pathways (Vert et al. 2008; Walcher and Nemhauser 2012; Chung and Choe 2013), but the function of these connections remained unclear.

More recently, a series of biochemical and genomic Arabidopsis experiments led to the postulation of a 'Central Growth Regulation Network' (CGRN) (Fan et al. 2014; Oh et al. 2014; Wang et al. 2014). According to this novel 'CGRN-theory', transcription regulators of $\mathrm{BR}$, auxin, GA and light (phytochrome) pathways interact directly at shared gene promoters to regulate gene expression and hypocotyl elongation. In addition, plant pathogens generate growth-inhibiting signals that modulate components of the CGRN to tip the balance between organ elongation and immunity (Wang 2012; Fan et al. 2014). It is likely that this CGRN also exists in the cells of maize seedlings, although positive evidence for this hypothesis is lacking.

\section{Conclusions and outlook}

In their classic monograph, Went and Thimann (1937) introduced the phrase "without auxin, no growth", a tenet that was extended and elaborated by subsequent generations of plant physiologists (Srivastava 2002). Five decades ago, the formula "no IAA-dependent cell elongation without the biosynthesis of GLPs" was coined, which was deduced on the basis of numerous sophisticated inhibitor studies (Nooden and Thimann 1963; Key 1964; Key and Ingle 1964; Key and Shannon 1964). Here, we have described the elaboration of this classical 'GLP-concept' with reference to organ development in maize, one of the model plants of early auxin research (Kriechbaumer 2006; Abel and Theologis 2010). The IAAinduced, Golgi-derived proteinaceous nano-particles that are incorporated into the growthlimiting outer epidermal wall (OEW) of the coleoptile have been characterized in detail (Fig. 3 ). Despite many efforts, the exact composition and functional significance of these putative GLPs remain unresolved (Edelmann and Schopfer 1989; Deng et al. 2012; Li et al. 2013).

However, the classic idea of GLPs is consistent with our current understanding of transcriptional regulation of cell elongation through RNA- and protein-biosynthesis. Based on genomic studies, GLP is not a single protein, but most likely a collection of a large 
number of proteins that are involved in cell wall synthesis, wall loosening, vesicle trafficking, cytoskeleton organization etc. In other words: IAA-mediated cell elongation involves the coordinated expression of a large set of genes and proteins.

We summarize recent evidence indicating that, in addition to auxin, brassinosteroids (BRs) are causally involved in the regulation of shoot growth in maize. Figure 6 depicts our current model of coleoptile- and mesocotyl elongation in dark-grown maize seedlings. In addition to an appropriate turgor pressure and an active $\left(\mathrm{O}_{2}\right.$-dependent $)$ cell metabolism, GLPs are involved in the regulation of IAA (and BR)-dependent cell expansion. Research is urgently needed to test whether the recently characterized 'Central Growth Regulation Network' (CGRN) deduced from data generated with Arabidopsis seedlings (Fan et al. 2014; Oh et al. 2014; Wang et al. 2014) also operates in maize. More work is required to further elucidated the hormonal interactions in the regulation of shoot growth in cereals such as Zea mays.

Corn is the most productive crop in the USA that is grown at high planting densities (Fig. 1 a). As a result, crop yield is influenced by phytochrome-mediated shade-avoidances responses that are based on growth processes regulated via both a modulation of intracellular auxin concentrations, and signal integration at the transcriptional level (Dubois et al. 2010; Kutschera and Briggs 2009, 2013; Wang et al. 2012, 2014).

\section{Acknowledgments}

This project was supported by the Alexander von Humboldt-Stiftung (AvH fellowships Stanford 2012/13 to U. K., Institute of Biology, University of Kassel, Germany), and grants from the US National Institute of Health (R01GM066258 to Z.-Y. W.).

\section{References}

Abel S, Theologis A (2010) Odyssey of auxin. Cold Spring Harb Perspect Biol 2:1-10

Bai M-Y, Shang J-Y, Oh E, Fan M, Bai Y, Zentella R, Sun T-P, Wang Z-Y (2012a) Brassinosteroid, gibberellin and phytochrome impinge on a common transcription module in Arabidopsis. Nat Cell Biol 14:810-817 [PubMed: 22820377]

Bai M-Y, Fan M, Oh E, Wang Z-Y (2012b) A triple helix-loop-helix/basic helix-loop-helix cascade controls cell elongation downstream of multiple hormonal and environmental signalling pathways in Arabidopsis. Plant Cell 24:4917-4929 [PubMed: 23221598]

Barker-Bridgers M, Ribnicky DM, Cohen JD, Jones AM (1998) Red-light-regulated growth. Changes in the abundance of indole-acetic acid in maize (Zea mays L.) mesocotyl. Planta 204:207-211

Baskin TI (2005) Anisotropic expansion of the plant cell wall. Annu Rev Cell Dev Biol 21:203-222 [PubMed: 16212493]

Bates GW, Cleland RE (1979) Protein synthesis and auxin-induced growth: Inhibitor studies. Planta 145:437-442 [PubMed: 24317859]

Becker D, Hedrich R (2002) Channelling auxin action: modulation of ion transport by indole-3-acetic acid. Plant Mol Biol 49:349-356 [PubMed: 12036259]

Benjamins R, Scheres B (2008) Auxin: The looping star in plant development. Annu Rev Plant Biol 59: 443-465. [PubMed: 18444904]

Bergfeld R, Speth V, Schopfer P (1988) Reorientation of microfibrils and microtubules at the outer epidermal wall of maize coleoptiles during auxin-mediated growth. Bot Acta 101:57-67

Borucka J, Fellner M (2012) Auxin binding proteins ABP1 and ABP4 are involved in the light- and auxin-induced down-regulation of phytochrome gene PHYB in maize (Zea mays L.) mesocotyl. Plant Growth Regul 68:503-509 
Briggs WR (2014) Phototropism: Some history, some puzzles, and a look ahead. Plant Physiol 164:1323 [PubMed: 24399823]

Brummell DA, Hall JL (1987) Rapid cellular responses to auxin and the regulation of growth. Plant Cell Environm 10:523-543

Burdach Z, Kurtyka R, Siemieniuk A, Karcz W (2014) Role of chloride ions in the promotion of auxin-induced growth of maize coleoptiles. Ann Bot 114:1023-1034 [PubMed: 25129632]

Chae K, Isaacs CG, Reeves PH, Maloney GS, Muday GR, Nagpal P, Reed JW (2012) Arabidopsis SMALL AUXIN UP RNA 63 promotes hypocotyl and stamen filament elongation. Plant J 71:684697 [PubMed: 22507274]

Chan J (2012) Microtubule and cellulose microfibril orientation during plant cell and organ growth. J Microscopy 247:23-32

Chapman EJ, Estelle M (2009) Mechanism of auxin-regulated gene expression in plants. Annu Rev Genet 43:265-285 [PubMed: 19686081]

Chung Y, Choe S (2013) The regulation of brassinosteroid biosynthesis in Arabidopsis. Crit Rev Plant Sci 32: 396-410.

Claussen M, Luthen H, Blatt M, Bottger M (1997) Auxin-induced growth and its linkage to potassium channels. Planta 201:227-234

Cleland RE (1971) Instability of the growth-limiting proteins of the Avena coleoptile and their pool size in relation to auxin. Planta 99:1-11 [PubMed: 24487443]

Cona A, Cenci F, Cervelli M, Federico R, Mariottini P, Moreno S, Angelini R (2003) Polyamine oxidase, a hydrogen peroxide-producing enzyme, is up-regulated by light and down regulated by auxin in the outer tissues of the maize mesocotyl. Plant Physiol 131:803-813 [PubMed: 12586904]

Cosgrove DJ (1997) Relaxation in a high-stress environment: the molecular bases of extensible cell walls and cell enlargement. Plant Cell 9:1031-1041 [PubMed: 9254929]

Cosgrove DJ (2005) Growth of the plant cell wall. Nat Rev Mol Cell Biol 6:850-861 [PubMed: 16261190]

Deng Z, Xu S, Chalkley RJ, Oses-Prieto JA, Burlingame AL, Wang Z-Y, Kutschera U (2012) Rapid auxin-mediated changes in the proteome of the epidermal cells in rye coleoptiles: Implications for the initiation of growth. Plant Biol 14:420-427 [PubMed: 22117532]

Deng Z, Oses-Prieto JA, Kutschera U, Tseng T-S, Hao L, Burlingame AL, Wang Z-Y, Briggs WR (2014) Blue light-induced proteomic changes in etiolated Arabidopsis seedlings. J Proteome Res 13: 2524-2523. [PubMed: 24712693]

Dietz A, Kutschera U, Ray PM (1990) Auxin enhancement of mRNAs in epidermis and internal tissues of the pea stem and its significance for control of elongation. Plant Physiol 93:432-438 [PubMed: 16667484]

Dubois PG, Olsefski GT, Flint-Garcia S, Setter TL, Hoekenga OA, Brutnell TP (2010) Physiological and genetic characterization of end-of-day far-red light response in maize seedlings. Plant Physiol 154:173-186 [PubMed: 20668057]

Edelmann HG, Schopfer P (1989) Role of protein and RNA synthesis in the inhibition of auxinmediated growth in coleoptiles of Zea mays L. Planta 179: 475-485. [PubMed: 24201771]

Edelmann HG, Kutschera U (1993) Rapid auxin-induced enhancement of protein biosynthesis in rye coleoptiles. J Plant Physiol 142:343-346

Edelmann HG, Bergfeld R, Schopfer P (1995) Effect of inhibition of protein glycosylation on auxininduced growth and the occurrence of osmiophilic particles in maize (Zea mays L.) coleotiles. J Exp Bot 46:1745-1752

Edelmann HG, Neinhuis C, Bargel H (2005) Influence of hydration and temperature on the rheological properties of plant cuticles and their impact on plant organ integrity. J Plant Growth Regul 24:116126

Fan M, Bai M-Y, Kim J-G, Wang T, Oh E, Chen L, Park CH, Son S-H, Kim S-K, Mudgett MB, Wang Z-Y (2014) The bHLH transcription factor HBI1 mediates the trade-off between growth and pathogen-associated molecular pattern-triggered immunity in Arabidopsis. Plant Cell 26: 828-841 [PubMed: 24550223]

Frankova L, Fry SC (2013) Biochemistry and physiological roles of enzymes that 'cut and paste' plant cell-wall polysaccharides. J Exp Bot 64:3519-3550 [PubMed: 23956409] 
Gao Q, Zhao M, Li F, Guo Q, Xing S, Wang W (2008) Expansins and coleoptile elongation in wheat. Protoplasma 233:73-81 [PubMed: 18726548]

Georgelis N, Yennawar NH, Cosgrove DJ (2012) Structural basis for entropy-driven cellulose binding by a type-A cellulose-binding module (CBN) and bacterial expansins. Proc Natl Acad Sci USA 109: 14830-14835 [PubMed: 22927418]

Goda H, Sawa S, Asami T, Fujioka S, Shimada Y, Yoshida S (2004) Comprehensive comparison of auxin-regulated and brassinosteroid-regulated genes in Arabidopsis. Plant Physiol 130:1319-1334

Hager A (2003) Role of the plasma membrane $\mathrm{H}^{+}$-ATPase in auxin-induced elongation growth: historical and new aspects. J Plant Res 116:483-505 [PubMed: 12937999]

Hartwig T, Chuck GS, Fujioka S, Klempien A, Weizbauer R, Potluri DPV, Choe S, Johal GS, Schulz B (2011) Brassinosteroid control of sex determination in maize. Proc Natl Acad Sci USA 108:19814-19819 [PubMed: 22106275]

Hartwig T, Corvalan C, Best NB, Budka JS, Zhu J-Y, Choe S, Schulz B (2012) Propiconazole is a specific and accessible brassinosteroid (BR) biosynthesis inhibitor for Arabidopsis and maize. PLoS ONE 7/5, e36625

Hao J, Yin Y, Fei S (2013) Brassinosteroid signalling network: implications on yield and stress tolerance. Plant Cell Rep 32:1017-1030 [PubMed: 23568410]

Hoffmann-Benning S, Klomparens KL, Kende H (1994) Characterization of growth-related osmiophilic particles in corn coleoptiles and deepwater rice internodes. Ann Bot. 74:563-572

Iino M (1982) Inhibitory action of red light on the growth of the maize mesocotyl: evaluation of the auxin hypothesis. Planta 156:388-395 [PubMed: 24272650]

Iino M, Carr DJ (1982) Sources of free IAA in the mesocotyl of etiolated maize seedlings. Plant Physiol 69:1109-1112 [PubMed: 16662352]

Jones AM, Cochran DS, Lamerson PM, Evans ML, Cohen JD (1991) Red light-regulated growth. I. Changes in the abundance of Indoleacetic Acid and 22-Kilodalton Auxin-Binding Protein in the maize mesocotyl. Plant Physiol 97:352-358 [PubMed: 11538374]

Karcz W, Burdach Z (2007) Effect of temperature on growth, proton extrusion and membrane potential in maize (Zea mays L.) coleoptile segments. Plant Growth Regul 52:141-150

Key JL (1964) Ribonucleic acid and protein synthesis are essential processes for cell elongation. Plant Physiol 39:365-370 [PubMed: 16655928]

Key JL (1969) Hormones and nucleic acid metabolism. Annu. Rev. Plant Physiol 20:449-474

Key JL, Ingle J (1964) Requirement for the synthesis of DNA-like RNA for the growth of excised plant tissue. Proc Natl Acad Sci USA, 52:1382-1388 [PubMed: 16591236]

Key JL, Shannon JC (1964) Enhancement by auxin of ribonucleic acid synthesis in excised soybean hypocotyl tissue. Plant Physiol 39:360-364 [PubMed: 16655927]

Kim Y-S, Kim T-W, Kim S-K (2005) Brassinosteroids are inherently biosynthesized in the primary roots of maize, Zea mays L. Phytochemistry 66:1000-1006 [PubMed: 15896368]

Kim T-W, Wang Z-Y (2010) Brassinosteroid signal transduction from receptor kinases to transcription factors. Annu Rev Plant Biol 61:681-704 [PubMed: 20192752]

Kriechbaumer V, Park WJ, Gierl A, Glawischnig E (2006) Auxin biosynthesis in maize. Plant Biol 8:334-339 [PubMed: 16807825]

Kutschera U (1994) The current status of the acid-growth hypothesis. New Phytol 126:549-569.

Kutschera U (2001) Stem elongation and cell wall proteins in flowering plants. Plant Biol 3:466-480

Kutschera U (2003) Auxin-induced cell elongation in grass coleoptiles: a phytohormone in action. Curr Topics Plant Biol 4:27-46

Kutschera U (2006) Acid growth and plant development. Science 311:952-953

Kutschera U (2008a) The outer epidermal wall: Design and physiological role of a composite structure. Ann Bot 101:615-621 [PubMed: 18258808]

Kutschera U (2008b) The pacemaker of plant growth. Trends Plant Sci 13:105-107 [PubMed: 18261951]

Kutschera U, Bergfeld R, Schopfer P (1987) Cooperation of epidermis and inner tissues in auxinmediated growth of maize coleoptiles. Planta 170:168-180 [PubMed: 24232875] 
Kutschera U, Briggs WR (2009) From Charles Darwin's botanical country-house studies to modern plant biology. Plant Biol 11:785-795 [PubMed: 19796355]

Kutschera U, Briggs WR (2012) Root phototropism: From dogma to the mechanism of blue light perception. Planta 235:443-452 [PubMed: 22293854]

Kutschera U, Briggs WR (2013) Seedling development in buckwheat and the discovery of the photomorphogenic shade-avoidance response. Plant Biol 15:931-940 [PubMed: 24112603]

Kutschera U, Deng Z, Oses-Prieto JA, Burlingame AL, Wang Z-Y (2010) Cessation of coleoptile elongation and loss of auxin sensitivity in developing rye seedlings. A quantitative proteomic analysis. Plant Signal Behav 5:509-517 [PubMed: 20234181]

Kutschera U, Edelmann HG (2005) Osmiophilic nanoparticles in epidermal cells of grass coleoptiles: Implications for growth and gravitropism. Rec Res Dev Plant Sci 3:1-14

Kutschera U, Niklas KJ (2007) The epidermal-growth-control theory of stem elongation: an old and a new perspective. J Plant Physiol 164:1395-1409 [PubMed: 17905474]

Kutschera U, Niklas KJ (2009) Evolutionary plant physiology: Charles Darwin's forgotten synthesis. Naturwissenschaften 96:1339-1354 [PubMed: 19763527]

Kutschera U, Niklas KJ (2013) Cell division and turgor-driven stem elongation in juvenile plants: A synthesis. Plant Sci 207:45-56 [PubMed: 23602098]

Kutschera U, Schopfer P (1986) Effect of auxin and abscisic acid on cell wall extensibility in maize coleoptiles. Planta 167:527-535 [PubMed: 24240369]

Kutschera U, Wang Z-Y (2012) Brassinosteroid action in flowering plants: a Darwinian perspective. J Exp Bot 63:3511-3522 [PubMed: 22547659]

Lamport DTA, Kieliszewski MJ, Chen Y, Cannon MC (2011) Role of the extension superfamily in primary cell wall architecture. Plant Physiol 156:11-19 [PubMed: 21415277]

Lamport DTA, Varnail P, Seal C (2014) Back to the future with the AGP-Ca2 ${ }^{+}$flux capacitor. Ann Bot 114: 1069-1085 [PubMed: 25139429]

Li; Dickerson TJ, Hoffmann-Benning S (2013) Contribution of proteomics in the identification of novel proteins associated with plant growth. J Proteome Res 12:4882-4891 [PubMed: 24028706]

Lipchinsky A (2013) How do expansins control plant growth? A model for cell wall loosening via defect migration in cellulose microfibrils. Acta Physiol Plant 35: 3277-3284

Lipchinsky A, Sharova EL, Medvedev SS (2013) Elastic properties of the growth-controlling outer cell walls of maize coleoptile epidermis. Acta Physiol Plant 35:2183-2191

Ljung K (2013) Auxin metabolism and homeostasis during plant development. Development 140:943950 [PubMed: 23404103]

Makarevitch I, Thompson A, Muehlbauer GJ, Springer NM (2012) Brd1 gene in maize encodes a brassinosteroid C-6 oxidase. PloS One 7:e30798 [PubMed: 22292043]

Markelz NH, Costich DE, Brutnell TP (2003) Photomorphogenic responses in maize seedling development. Plant Physiol 133:1574-1591

McQueen-Mason S, Durachko DM, Cosgrove DJ (1992) Two endogenous proteins that induce cell wall extension in plants. Plant Cell 4: 1425-1433 [PubMed: 11538167]

Mer CL (1951) A critical study of the auxin theory of growth regulation in the mesocotyl of Avena sativa. Ann Bot 15:179-207

Mori Y, Nishimura T, Koshiba T (2005) Vigorous synthesis of indole-3-acetic acid in the very apical tip leads to a constant basipedal flow of the hormone in maize coleoptiles. Plant Sci 164:467-473

Nemhauser JL, Mockler TC, Chory J (2004) Interdependency of brassinosteroid and auxin signalling in Arabidopsis. PloS Biol 2:e258 [PubMed: 15328536]

Niklas KJ, Kutschera U (2009) The evolutionary development of plant body plans. Funct. Plant Biol 36:682-695

Niklas KJ, Kutschera U (2010) The evolution of the land plant life cycle. New Phytol 185:27-41 [PubMed: 19863728]

Niklas KJ, Kutschera U (2012) Plant development, auxin, and the subsystem incompleteness theorem. Front Plant Sci 3/37:1-11 
Nishimura T, Toyooka K, Sato M, Matsumoto S, Lucas MM, Stonad M, Baluska F, Koshiba T (2011) Immunohistochemical observation of indole-3-acetic acid at the IAA synthetic maize coleoptile tip. Plant Signal Behav 6:2013-2022 [PubMed: 22112455]

Noodén LD, Thimann KV (1963) Evidence for a requirement for protein synthesis for auxin-induced cell enlargement. Proc Natl Acad Sci USA 50:194-200 [PubMed: 16591111]

Oh E, Zhu J-Y, Bai M-Y, Arenhart RA, Sun Y, Wang Z-Y (2014) Cell elongation is regulated through a central circuit of interacting transcription factors in the Arabidopsis hypocotyl. eLife 107554

Okamoto-Nakazato A (2002) A brief note on yieldin, a wall-bound protein that regulates the yield threshold of the cell wall. J Plant Res 115:309-313 [PubMed: 12582736]

Olivier NB (2014) Structural biology: Ribosome revelations. Nature 513:491-492 [PubMed: 25209662]

Penny P (1971) Growth-limiting proteins in relation to auxin-induced elongation in lupin hypocotyls. Plant Physiol 48:720-723 [PubMed: 16657867]

Rudnicka M, Polak M, Karcz W (2014) Cellular responses to naphthoquinones: juglone as a case study. Plant Growth Regul 72:239-248

Samajova O, Samaj J, Volkmann D, Edelmann HG (1998) Occurrence of osmiophilic particles is correlated to elongation growth in higher plants. Protoplasma 202:185-191

Savaldi-Goldstein S, Peto C, Chory J (2007) The epidermis both drives and restricts plant shoot growth. Nature 446:199-202 [PubMed: 17344852]

Schindler T; Bergfeld R, Hohl M, Schopfer P (1994) Inhibition of Golgi-apparatus function by brefeldin $\mathrm{A}$ in maize coleoptiles and its consequences on auxin-mediated growth, cell-wall extensibility and secretion of cell-wall proteins. Planta 192: 404-413

Shishova M, Lindberg S (2010) A new perspective on auxin perception. J Plant Physiol 167: 417-422 [PubMed: 20176409]

Schneider-Poetsch T, Ju J, Eyler DE, Dang Y, Bhat S, Merrick WC, Green R, Shen B, Liu JO (2010) Inhibition of eukaryotic translation elongation by cycloheximide and lactimidomycin. Nat Chem Biol 6:209-217 [PubMed: 20118940]

Schopfer P (1993) Determination of auxin-dependent pH changes in coleoptile cell walls by a nullpoint method. Plant Physiol 103:351-357 [PubMed: 12231942]

Schopfer P (2006) Biomechanics of plant growth. Amer J Bot 93:1415-1425 [PubMed: 21642088]

Schopfer P, Lapierre C, Nolte T (2001) Light-controlled growth of the maize seedling mesocotyl: Mechanical cell-wall changes in the elongation zone and related changes in lignification. Physiol Plant 111:83-92

Sekimata K, Han SY, Yoneyama K, Takeuche Y, Yoshida S et al. (2002) A specific and potent inhibitor of brassinosteroid biosynthesis possessing a dioxolane ring. J Agric Food Chem 50:3486-3490 [PubMed: 12033815]

Shannon JC, Hanson JB, Wilson CM (1964) Ribonuclease levels in the mesocotyl tissue of Zea mays as a function of 2,4-Dichlorophenoxyacetic Acid application. Plant Physiol 39:804-809 [PubMed: 16656005]

Song Y (2014) Insights into the mode of action of 2,4-dichlorophenoxyacetic acid (2,4-D) as an herbicide. J Integr Plant Biol 56:106-113 [PubMed: 24237670]

Srivastava LM (2002) Plant Growth and Development. Hormones and Environment. Academic Press, San Diego

Teale WD, Poponov IA, Palme K (2006) Auxin in action: signaling, transport and the control of plant growth and development. Nat Rev Mol Cell Biol 7:847-859 [PubMed: 16990790]

Woodward AW, Bartel B (2005) Auxin: regulation, action, and interaction. Ann Bot 95: 707-735. [PubMed: 15749753]

Valdivia ER, Wu Y, Li L-C, Cosgrove DJ, Stephenson AG (2007) A group-1 grass pollen allergen influences the outcome of pollen competition in maize. PLoS One 2 (1): e154. [PubMed: 17225858]

Vanderhoef LN, Briggs WR (1978) Red light-inhibited mesocotyl elongation in maize seedlings. 1. The auxin hypothesis. Plant Physiol 61:534-537 [PubMed: 16660331]

van Overbeek J (1936) Growth hormone and mesocotyl growth. Rec Trav Bot Neerl 33:333-340 
Vaughn KC (2002) Attachment of the parasitic weed dodder to the host. Protoplasma 219:227-237 [PubMed: 12099223]

Visnovitz T, Touati M, Miller AJ, Fricke W (2013) Apoplast acidification in growing barley (Hordeum vulgare L.) leaves. J. Plant Growth Regul 32:131-139

Walcher CL, Nemhauser JL (2012) Bipartite promoter element required for auxin response. Plant Physiol 158:273-282 [PubMed: 22100645]

Wang W, Bai M-Y, Wang Z-Y (2014) The brassinosteroid signaling network - a paradigm of signal integration. Curr Opin Plant Biol 21:147-153 [PubMed: 25139830]

Wang Z-Y (2012) Brassinosteroids modulate plant immunity at multiple levels. Proc Natl Acad Sci USA 109:7-8 [PubMed: 22198764]

Wang Z-Y, Bai M-Y, Oh E, Zhu J-Y (2012) Brassinosteroid signaling network and regulation of photomorphogenesis. Annu Rev Genet 46:701-724 [PubMed: 23020777]

Went FW (1928) Wuchsstoff und Wachstum. Rec Trav Bot Neerl 25:1-116

Went FW, Thimann KV (1937) Phytohormones. The Macmillan Company, New York

Xu T, Wen M, Nagawa S, Fu Y, Chen JG, Wu MJ, Perrot-Rechenmann C, Friml J, Jones AM, Yang Z (2010) Cell surface and rho GTPase-based auxin signaling controls cellular integration in Arabidopsis. Cell 143:99-110 [PubMed: 20887895]

Yahalom A, Epel BL, Glinka Z, MacDonald IR, Gordon DC (1987) A kinetic analysis of phytochrome controlled mesocotyl growth in Zea mays seedlings. Plant Physiol 84:390-394 [PubMed: 16665449]

Yahalom A, Epel BL, Glinka Z (1988) Photomodulation of mesocotyl elongation in maize seedlings: Is there a correlative relationship between phytochrome, auxin and cell wall extensibility? Physiol Plant 72:428-433

Zažimalovà E, Petràšek J, Benkovà (eds) (2014) Auxin and its role in plant development. SpringerVerlag, Wien

Zhao M-R, Li F, Fang Y, Gao Q, Wang W (2011) Expansin-regulated cell elongation is involved in the drought tolerance of wheat. Protoplasma 248:313-323 [PubMed: 20559851]

Zhao Y (2012) Auxin biosynthesis: a simple two-step pathway converts tryptophan to Indole-3-acetic acid in plants. Mol Plant 5:334-338 [PubMed: 22155950]

Zhu J-Y, Sae-Seaw J, Wang Z-Y (2013) Brassinosteroid signalling. Development 140:1615-1620 [PubMed: 23533170] 

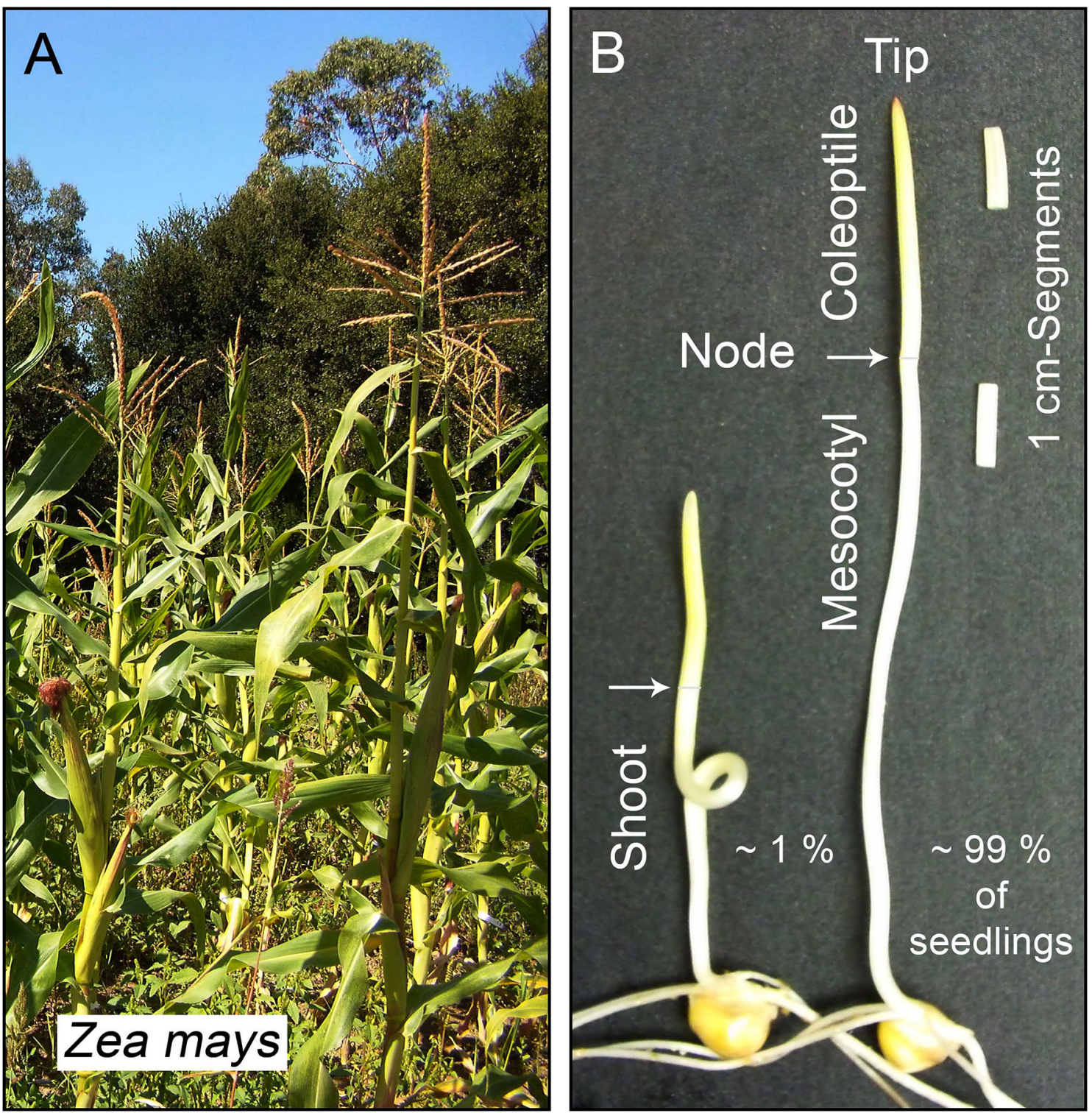

Fig. 1.

Maize (Zea mays) is the most important crop plant of the USA and a model organism for the elucidation of the mechanisms governing plant growth. Photograph of a corn field, September 2013, Stanford, California (a). The plant hormone auxin (IAA) was isolated in 1946 from corn kernels, and maize has long been the principal monocot for studies on the mode of IAA biosynthesis. Two dark-grown, 4-day-old maize seedlings, with curved (left) and straight mesocotyl, respectively, are depicted (right) (b). Among 100 seedlings, ca. $1 \%$ displayed a "curly" mesocotyl. Excised segments, cut below the tip of the coleoptile or the node, respectively, are also shown 

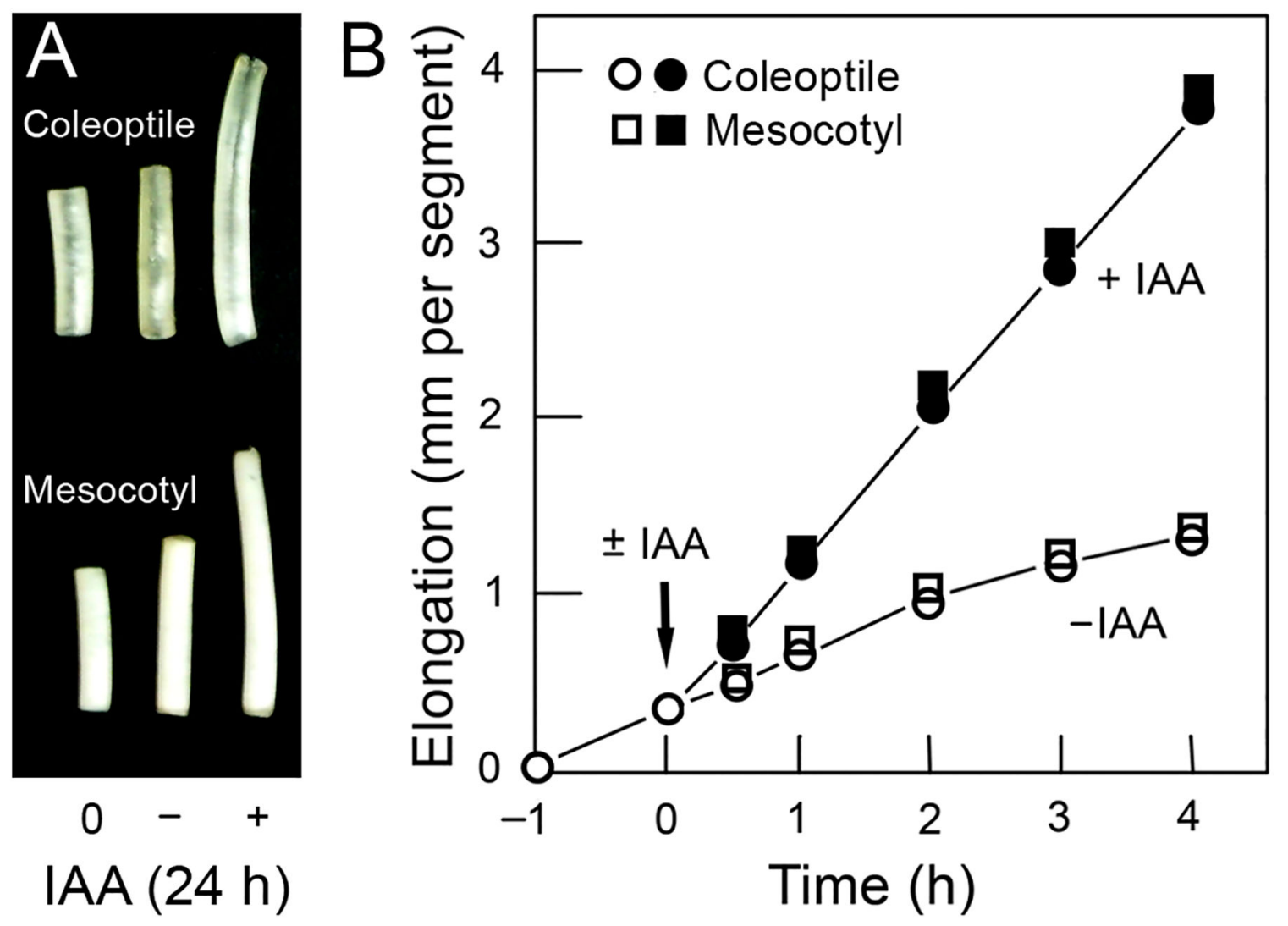

Fig. 2.

Segment test to study the action of the phytohormone auxin (IAA) in grass coleoptiles. Growth response of excised mesocotyl- and coleoptile segments (10 $\mathrm{mm}$ in length) after addition of IAA $(10 \mu \mathrm{M}, 24 \mathrm{~h})$ (a) and short-term growth response, measured using the same plant material (b) $\left(25^{\circ} \mathrm{C}\right.$, darkness; incubation medium: distilled water); $\mathrm{n}=12$ replicates each. The error bars are smaller than the size of the symbols 

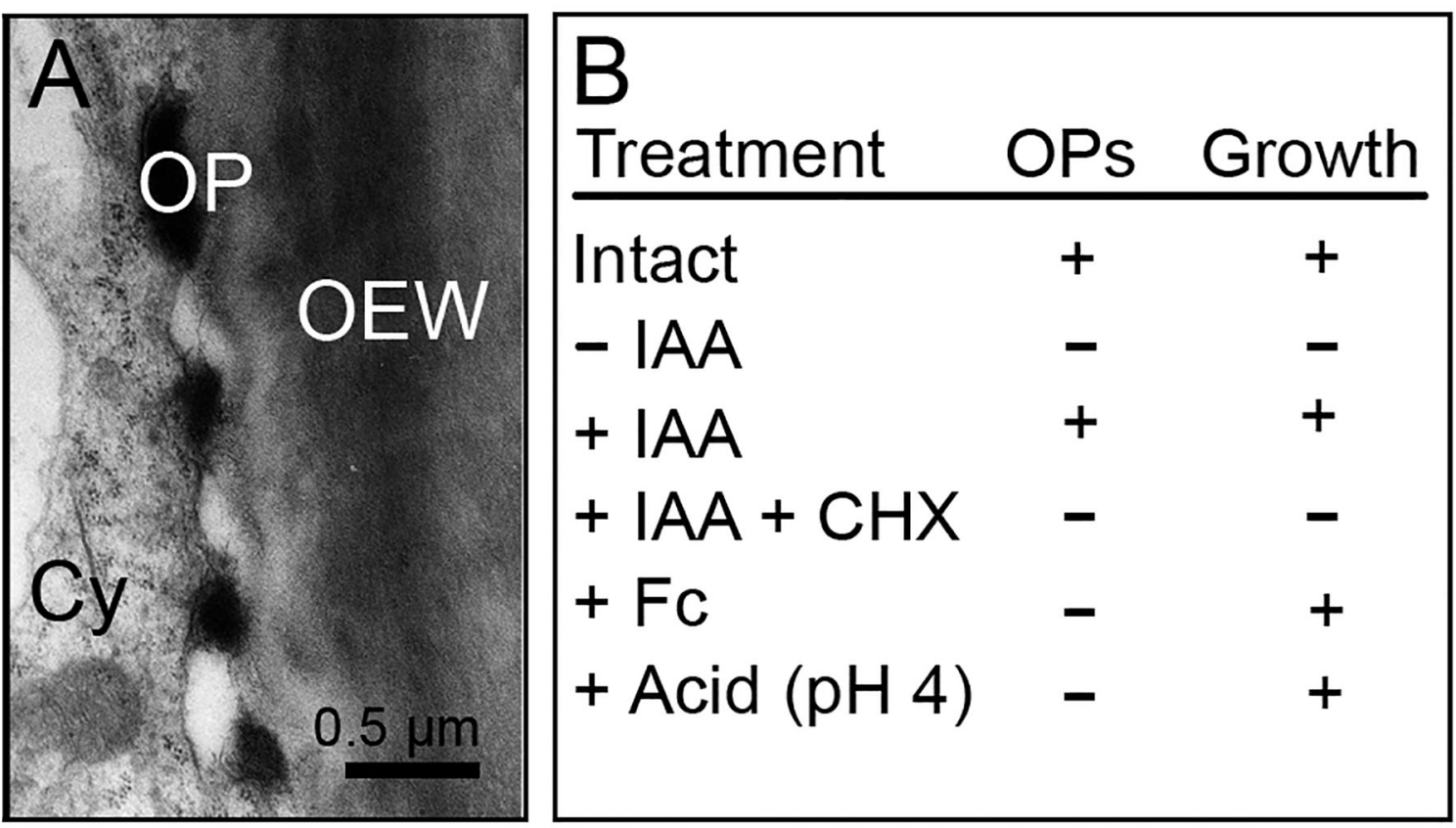

Fig. 3.

Auxin-induced, growth-related osmiophilic nano-particles along the expansion-limiting peripheral cell wall in maize coleoptiles. Transmission electron micrograph showing four osmiophilic particles (OP) in the periplasmic space between the plasma membrane and the outer epidermal wall (OEW) (a) and gazing section (b), showing numerous OPs and cortical microtubules (arrows) (a: $1 \mathrm{~h}+\mathrm{IAA}, 10 \mu \mathrm{M} ; \mathrm{b}: 0.5 \mathrm{~h}+\mathrm{IAA}, 10 \mu \mathrm{M})$. The table (c) documents the relationship between the occurrence of OPs, which originate in the cytoplasm (Cy), and coleoptile elongation. $\mathrm{CHX}=$ cycloheximide, $\mathrm{Fc}=$ fusicoccin, IAA $=$ auxin (treatment: $1 \mathrm{~h} \pm$ IAA, $10 \mu \mathrm{M}$, or Fc $1 \mu \mathrm{M}$, respectively) (adapted from Bergfeld et al. 1988) 


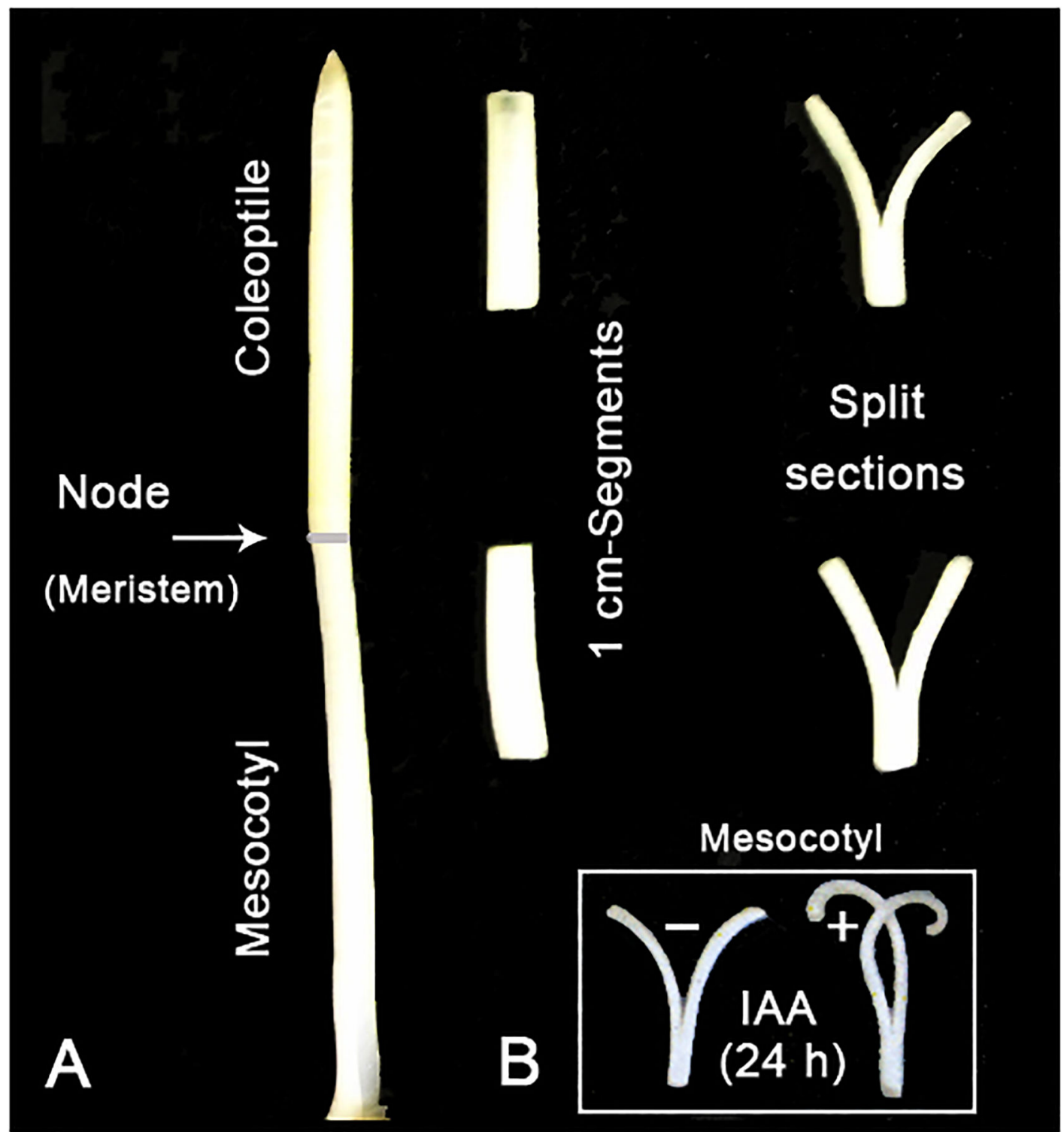

Fig. 4.

Biophysical basis of cell elongation in the coleoptile and mesocotyl of maize (Zea mays) seedlings. Split sections (length: $1 \mathrm{~cm}$ ), placed on water, display a rapid outward bending response, indicating that the outer epidermal wall is under longitudinal tension (a). Upon incubation in IAA $(10 \mu \mathrm{M})$ for $24 \mathrm{~h}$, mesocotyl sections respond with the typical inward bending, as documented before for coleoptile segments (b). This result indicates that the epidermis is the primary target tissue for IAA action in this organ 


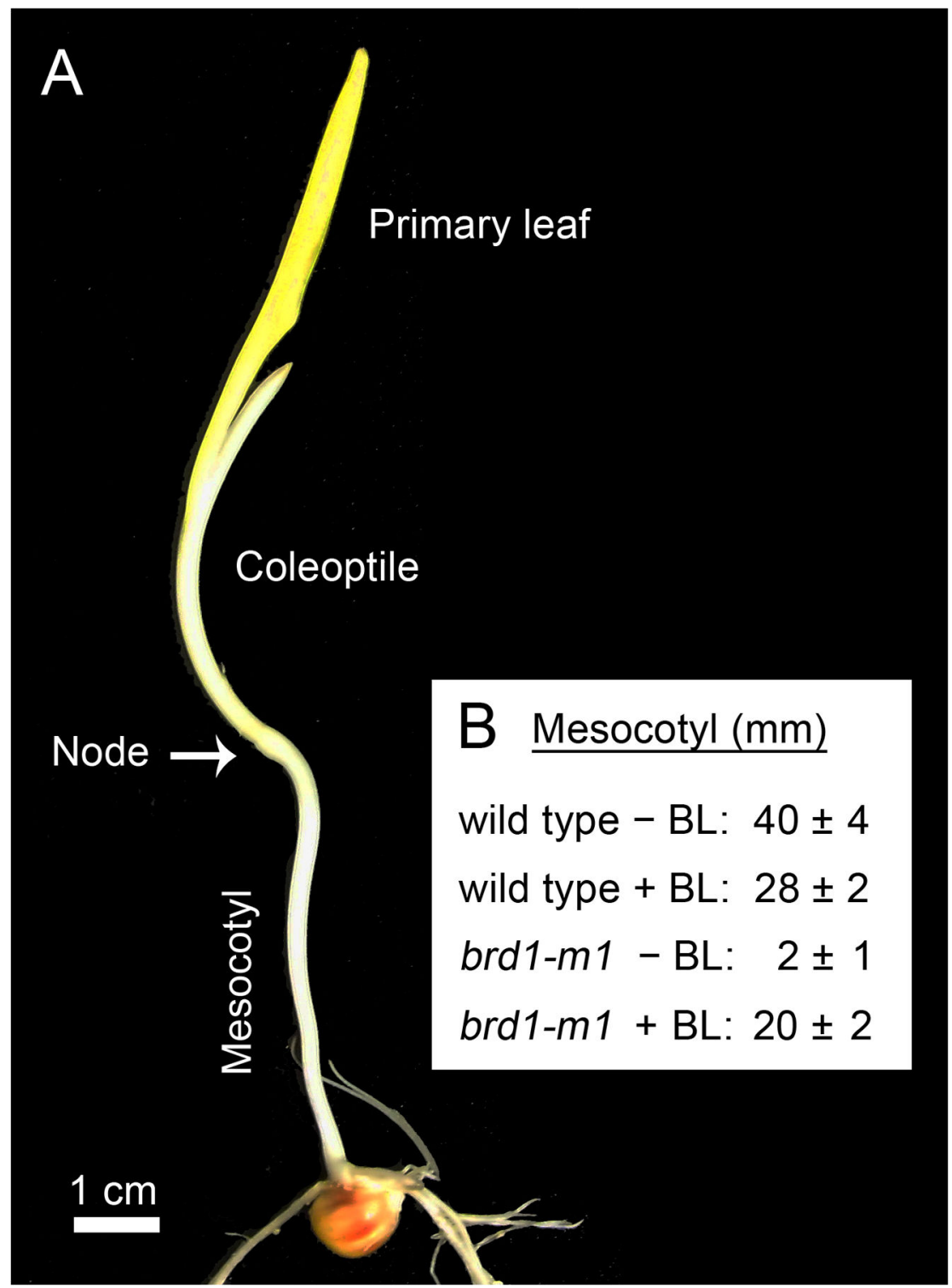

Fig. 5.

Morphology of a 12-day-old etiolated maize seedling (Zea mays, wild type), and effect of brassinolide (BL) on mesocotyl growth. Seeds of wild type (wt) plants and a maize brassinosteroid-deficient mutant ( $b r d 1-m I$ ) were germinated and grown in darkness on MSmedium in the absence or presence $( \pm)$ of brassinolide (BL, $1 \mu \mathrm{M})$. Representative 12-d-old plant (a) and quantitative data documenting the role of brassinosteroids in the regulation of mesocotyl growth in etiolated maize seedlings $(n=6)(b)$ (original photograph, a; data adapted from Makarevitch et al. 2012; b) 


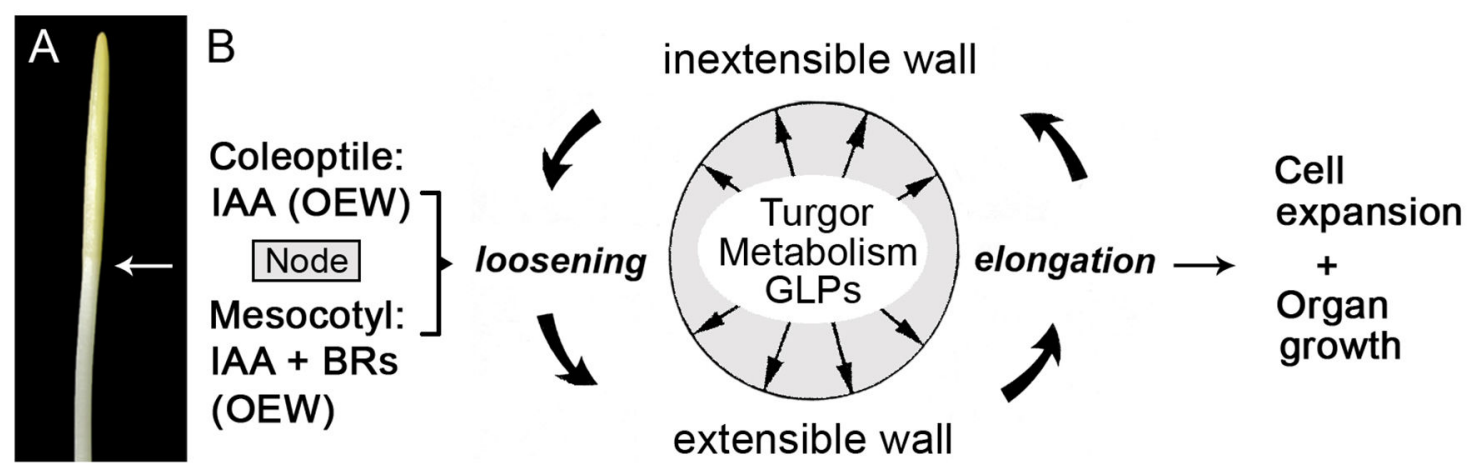

Fig. 6.

Photograph of the shoot of an etiolated maize (Zea mays) seedling (a) and illustration of the auxin (IAA)-brassinosteroid (BR)-hypothesis of mesocotyl elongation (b). Coleoptile and mesocotyl are separated by the node, which consist of the meristematic tissue of the shoot. In both the coleoptile and the mesocotyl, organ growth is caused by the loosening/elongation of the thickened outer epidermal wall (OEW). This process, which is regulated by IAA (and BRs), depends on (1.) turgor pressure which must be maintained via osmoregulatory processes (2.), $\mathrm{O}_{2}$-fuelled metabolic activity of the cells, and (3.) the presence of growthlimiting proteins (GLPs) (adapted from Niklas and Kutschera 2012) 